\title{
Updated Taxonomy for the Network and Service Management Research Field
}

\author{
Jeroen van der Hooft - Maxim Claeys . \\ Niels Bouten . Tim Wauters . \\ Jürgen Schönwälder • Aiko Pras • \\ Burkhard Stiller . Marinos Charalambides . \\ Rémi Badonnel • Joan Serrat . \\ Carlos Raniery Paula dos Santos . \\ Filip De Turck
}

Received: date / Accepted: date

\begin{abstract}
Network and service management is an established research field within the general area of computer networks. A few years ago, an initial taxonomy, organizing a comprehensive list of terms and topics, was established through interviews with experts from both industry and academia. This taxonomy has since been used to better partition standardization efforts, identify classes of managed objects and improve the assignment of reviewers to papers submitted in the field. Because the field of network and service management is rapidly evolving, a biyearly update of the taxonomy was proposed. In this paper, a large-scale questionnaire is presented which was answered by experts in the field, evaluating the relevance of each individual topic for the next five years. Missing topics, which are likely to become relevant over the next few years, are identified as well. Furthermore, an analysis is performed of the records of papers submitted to major conferences in the area. Based on the obtained results, an updated version of the taxonomy is proposed.
\end{abstract}

Jeroen van der Hooft · Niels Bouten · Tim Wauters · Filip De Turck

Ghent University - imec, Ghent, Belgium

E-mail: jeroen.vanderhooft@ugent.be

Maxim Claeys

University of Antwerp - imec, Antwerp, Belgium

Jürgen Schönwälder

Jacobs University Bremen, Bremen, Germany

Aiko Pras

University of Twente, Enschede, The Netherlands

Burkhard Stiller

University of Zürich, Zürich, Switzerland

Marinos Charalambides

University College London, London, United Kingdom

Rémi Badonnel

University of Lorraine, Nancy, France

Joan Serrat

Polytechnic University of Catalonia, Barcelona, Spain

Carlos Raniery Paula dos Santos

Federal University of Santa Maria, Santa Maria, Brazil 
Keywords Network and Service Management - Research Topics - Taxonomy · Analysis · Questionnaire · Conference Proceedings

\section{Introduction}

Network and service management has established itself as a research field in the general area of computer networks. Originally, the Association for Computing Machinery (ACM) created a multi-level classification system which includes the keywords Network Services, Network Management and Network Monitoring [I]. This classification, however, does not provide any details to further structure the field of network and service management. For this reason, a new taxonomy has been proposed by a joint effort of the Flamingo FP7 Project and the Committee of Network Operations and Management (CNOM) of the Communications Society (COMSOC) of the Institute of Electrical and Electronics Engineers (IEEE) and the Working Group 6.6 of the International Federation of Information Processing (IFIP) [Z]. A total of 7 categories and 57 topics are identified, covering the different types of network, service and business management, and the technologies and methods applied in the field. The resulting taxonomy has since been used to better partition standardization efforts, identify classes of managed objects and improve the assignment of reviewers to papers submitted in the field. Because the field is rapidly evolving, regular updates to this taxonomy are required: small updates (i.e., adding topics) should be incorporated at least every two years, while thorough updates (i.e., adding, removing and potentially merging topics) should be made every five years $[\boldsymbol{Z}]$. In this work, an updated version of the network and service management taxonomy is proposed, based on an analysis of established and emerging topics in the field.

The remainder of this paper is organized as follows. In Sect. 叉, the original taxonomy of the network and service management field is presented. In Sect. B, a detailed description of a questionnaire on the taxonomy is discussed. This questionnaire was answered by 154 experts from industry and academia, allowing to evaluate the interest in the topics of the taxonomy. A few minor changes to the taxonomy are presented as well, which were made based on discussions within the

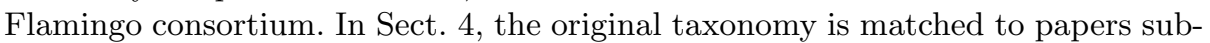
mitted to the major conferences in the field (i.e., NOMS, IM and CNSM). Based on the obtained results from the questionnaire and the analysis of paper submissions, an updated version of the taxonomy is proposed in Sect. [. Finally, Sect. [ concludes this paper.

\section{Original Network and Service Management Taxonomy}

In 2015, a new taxonomy for the network and service management field was proposed $[2]$. Different topics are assigned to one of seven categories, creating a twolevel taxonomy. The first three categories deal with what is being managed, more specifically:

1. Network Management: 'What kind of network is being managed?'

2. Service Management: 'What kind of service is being managed?'

3. Business Management: 'How does management relate to business aspects?' 
Table 1 Original network and service management taxonomy [그.
1. Network Management
- Ad-Hoc Networks
5. Management Approaches
- Centralized Management
- Wireless and Mobile Networks
- Distributed Management
- IP Networks
- Local Area Networks
- Optical Networks
- Autonomic and Self Management
- Policy-Based Management
- Federated Network Management
- Pro-Active Management
- Overlay Networks
- Virtual Networks
- Software-Defined and Programmable Networks
- Data Center Networks
- Smart Energy Grids
2. Service Management
- Multimedia Services
- Data Services
- Hosting (Virtual Machines)
- Grid Services
- Cloud Services
- Resource Provisioning and Management
- QoE-Centric Management
- Energy-Aware Network Management
- Service Discovery, Migration, and Orchestration
3. Business Management
- Legal and Ethical Issues
- Process Management
6. Technologies
- Protocols
- Middleware
- Mobile Agents
- Peer-to-Peer
- Grids
- Data, Information, and Semantic Modeling
- Cloud Computing
- Internet of Things
- Human-Machine Interaction
- Operations and Business Support Systems
7. Methods
- Control Theories
- Optimization Theories
- Economic Theories
- Machine Learning and Genetic Algorithms
4. Functional Areas
- Fault Management
- Configuration Management
- Accounting Management
- Performance Management
- Security Management
- SLA Management
- Event Management
- Logics
- Probabilistic, Stochastic Processes, Queuing Theory
- Simulation
- Experimental Approach
- Prototype Design
- Monitoring and Measurements
- Data Mining and (Big) Data Analytics

The fourth category deals with the functional areas:

4. Functional Areas: 'Which functional areas are covered?'

The last three categories address how something is managed:

5. Management Approaches: 'How is network and service management achieved?'

6. Technologies: 'Which technologies are used in the management process?'

7. Methods: 'What methods are used to address the management problem?'

The original taxonomy is shown in Table $\square$. In the next sections, an analysis is performed of relevant and emerging topics in the field, and an updated version of the taxonomy is proposed. 
Table 2 Five groups of participants from industry.

\begin{tabular}{lc}
\hline Industry Group & Participants \\
\hline Network provider & 12 \\
Network equipment provider & 16 \\
Cloud system provider & 3 \\
Software application provider & 7 \\
Other & 11 \\
\hline
\end{tabular}

Table 3 Geographic distribution of the participants.

\begin{tabular}{lcccc}
\hline Continent & Industry & Academia & Total & Total [\%] \\
\hline Asia & 4 & 4 & 8 & 5.19 \\
Europe & 32 & 81 & 113 & 73.38 \\
North America & 13 & 9 & 22 & 14.29 \\
South America & 0 & 8 & 8 & 5.19 \\
\hline
\end{tabular}

Table 4 Distribution of the level of experience in the management of networks and services of the participants.

\begin{tabular}{lcccc}
\hline Exp. [years] & Industry & Academia & Total & Total [\%] \\
\hline $0-5$ & 6 & 29 & 35 & 22.73 \\
$5-10$ & 10 & 28 & 38 & 24.68 \\
$10-15$ & 10 & 19 & 29 & 18.83 \\
$15-20$ & 8 & 12 & 20 & 12.99 \\
$20+$ & 15 & 17 & 32 & 20.78 \\
\hline
\end{tabular}

\section{Analysis of Taxonomy Topics Based on Questionnaire}

To identify required changes to the existing taxonomy, international experts from industry and academia were invited to participate in a questionnaire. Each participant was asked to provide his or her demographical information, including the level of experience, both in network and service management specifically, the background (industry or academia) and geographical location of the current employment (continent). In total, 154 people in the survey, out of which 49 from industry and 105 from academic institutes. As illustrated in Table $\boldsymbol{\nabla}$, the participants from industry can be classified in five groups, covering network, network

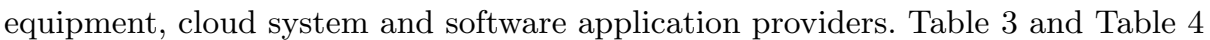
show the geographic distribution and the distribution of the level of experience in the field of the participants, respectively.

Before sending out the questionnaire, the original taxonomy was slightly altered based on discussions during CNOM/IFIP WG 6.6 and Flamingo project meetings. Changes cover both moving topics to another category, in order to better fit the semantics of the categorization described above, and adding new emerging topics, in order to account for new research directions. The following topics were moved to another category:

- Internet of Things is moved from category 6. Technologies to category 1. Network Management;

- QoE-Centric Management is moved from category 2. Service Management to category 5. Management Approaches; 


\begin{tabular}{l} 
Network Management * \\
"What kind of network is being managed?" \\
$\begin{array}{l}\text { Ad-hoc networks } \\
\text { Wireless \& mobile } \\
\text { networks }\end{array}$ \\
\hline \begin{tabular}{l} 
IP networks \\
\hline LANs
\end{tabular} \\
\hline Optical networks
\end{tabular}

Fig. 1 Screenshot of the taxonomy questionnaire for the category Network Management.

- Resource Provisioning and Management is moved from category 2. Service Management to category 6. Technologies;

- Service Discovery, Migration and Orchestration is moved from category 2. Service Management to category 6. Technologies.

The following emerging topics were added:

- Internet of Things Services was added to category 2. Service Management;

- Security Services was added to category 2. Service Management;

- Regulatory Perspective was added to category 3. Business Management;

- Economic Aspects was added to category 3. Business Management;

- Software-Defined Networking was added to category 6. Technologies;

- Network Function Virtualization was added to category 6. Technologies.

A screenshot of the taxonomy questionnaire for the category Network Management is presented in Figure $\square$. For each of the seven categories of topics covered by the taxonomy, the participant was asked to indicate which topics should be addressed by the network and service management research community during the next five years (2016-2020), on a scale from 0 (highly irrelevant topic) to 5 (highly relevant topic). Given the broad range of topics presented in the taxonomy, the participant was given the option to not express an opinion. For each category, the participant was also asked to propose important topics which are not yet listed in the current taxonomy. The results of this survey are presented and discussed below. 
Table 5 Topics considered important by academia. Ten of those topics are considered important by industry and two topics are not $(\dagger)$. Results denote the average rating given to each of the topics in the taxonomy (on a scale from 0 to 5 ) and its standard deviation, the percentage of abstentions (A) and the percentage of times the maximum rating was assigned (M).

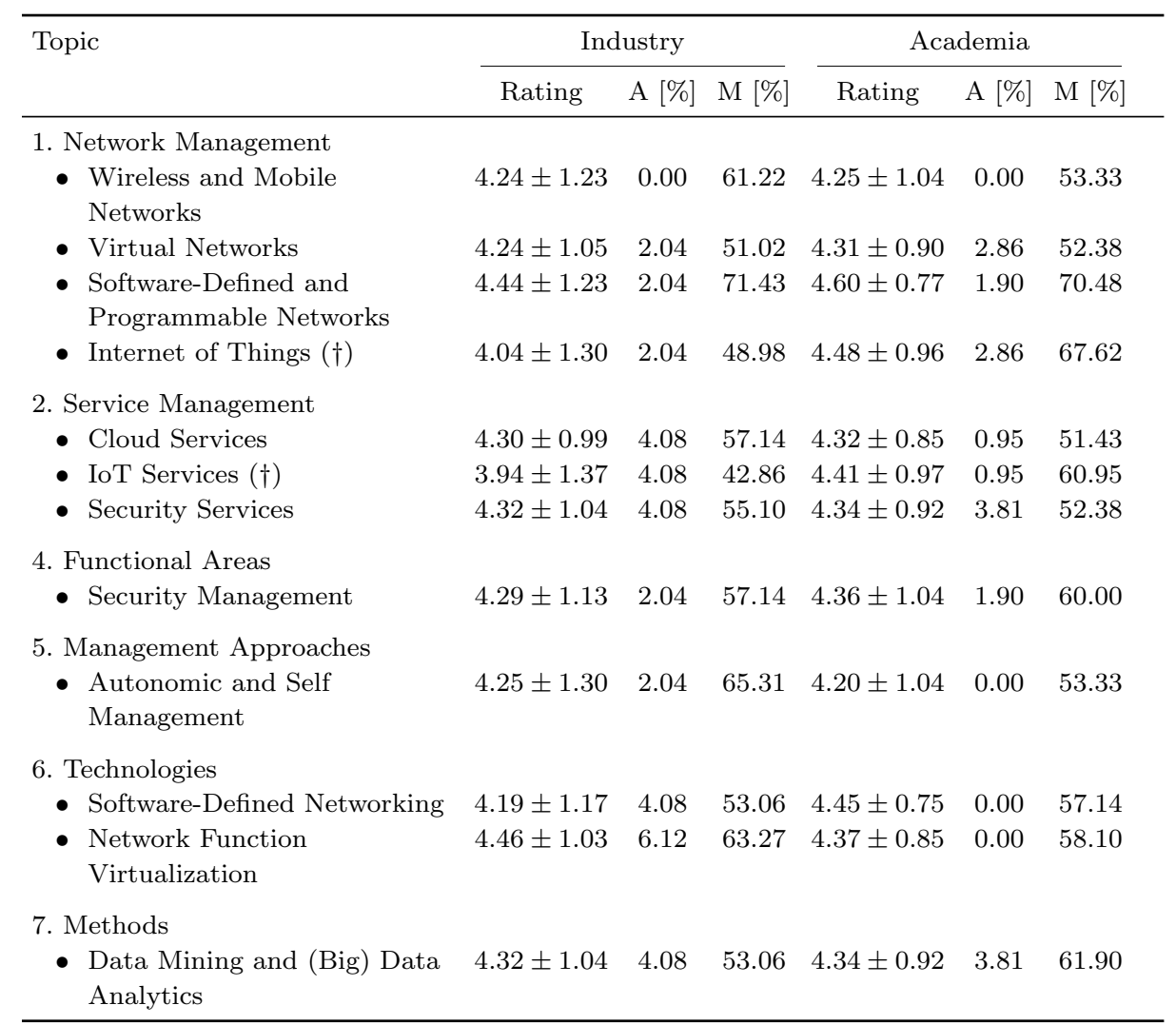

\subsection{Analysis of Important Topics}

The results of the survey allow to select the most important topics, both for industry and academia. An important topic is defined as a topic that received the maximum rating from at least $50 \%$ of the participants. Table $\$$ lists the ten topics which are considered important to both industry and academia, and the two topics which are considered important to academia only.

For most of the identified topics, such as Virtual Networks and SoftwareDefined and Programmable Networks, the average rating for industry and academia are similar. However, for others there is a significant bias towards one of the groups. Wireless and Mobile Networks, Cloud Services, Autonomic and Self Management and Network Function Virtualization are very important for industry, while Software-Defined Networking and Data Mining and (Big) Data Analytics are more important for academia. This indicates that, although general directions are the same, some differences between industry and academia still exist in the field of network and service management. 
Table 6 Topics considered less important by academia. Nine of those topics are considered less important by industry and one topic is not $(\dagger)$. Results denote the average rating given to each of the topics in the taxonomy (on a scale from 0 to 5 ) and its standard deviation, the percentage of abstentions (A) and the percentage of times a rating of 1 or 2 was assigned (M).

\begin{tabular}{|c|c|c|c|c|c|c|}
\hline \multirow[t]{2}{*}{ Topic } & \multicolumn{3}{|c|}{ Industry } & \multicolumn{3}{|c|}{ Academia } \\
\hline & Score & $\mathrm{A}[\%]$ & $\mathrm{M}[\%]$ & Score & $\mathrm{A}[\%]$ & $\mathrm{M}[\%]$ \\
\hline $\begin{array}{l}\text { 1. Network Management } \\
\text { - Ad-Hoc Networks } \\
\text { - Local Access Networks }\end{array}$ & $\begin{array}{l}2.81 \pm 1.56 \\
2.91 \pm 1.21\end{array}$ & $\begin{array}{c}12.24 \\
4.08\end{array}$ & $\begin{array}{l}32.65 \\
38.78\end{array}$ & $\begin{array}{l}2.90 \pm 1.39 \\
2.46 \pm 1.20\end{array}$ & $\begin{array}{l}4.76 \\
1.90\end{array}$ & $\begin{array}{l}33.33 \\
50.48\end{array}$ \\
\hline $\begin{array}{l}\text { 2. Service Management } \\
\text { - Data Services } \\
\text { - Grid Services }\end{array}$ & $\begin{array}{l}3.13 \pm 1.47 \\
2.78 \pm 1.28\end{array}$ & $\begin{array}{l}2.04 \\
8.16\end{array}$ & $\begin{array}{l}42.86 \\
40.82\end{array}$ & $\begin{array}{l}2.86 \pm 1.24 \\
2.93 \pm 1.31\end{array}$ & $\begin{array}{l}0.95 \\
5.71\end{array}$ & $\begin{array}{l}38.10 \\
34.29\end{array}$ \\
\hline $\begin{array}{l}\text { 3. Business Management } \\
\text { - Ethical Issues }\end{array}$ & $2.98 \pm 1.41$ & 8.16 & 30.61 & $2.95 \pm 1.34$ & 4.76 & 34.29 \\
\hline $\begin{array}{l}\text { 4. Functional Areas } \\
\text { - Accounting Management }\end{array}$ & $2.87 \pm 1.33$ & 6.12 & 36.73 & $2.93 \pm 1.37$ & 4.76 & 36.19 \\
\hline $\begin{array}{l}\text { 5. Management Approaches } \\
\text { - Centralized Management }(\dagger)\end{array}$ & $3.63 \pm 1.37$ & 4.08 & 20.41 & $3.03 \pm 1.40$ & 0.95 & 57.14 \\
\hline $\begin{array}{l}\text { 6. Technologies } \\
\text { - Mobile Agents } \\
\text { - Peer-to-Peer } \\
\text { - Grids }\end{array}$ & $\begin{array}{l}2.82 \pm 1.50 \\
2.41 \pm 1.50 \\
2.15 \pm 1.48\end{array}$ & $\begin{array}{l}10.20 \\
10.20 \\
16.33\end{array}$ & $\begin{array}{l}32.65 \\
40.82 \\
46.94\end{array}$ & $\begin{array}{l}2.73 \pm 1.48 \\
2.59 \pm 1.34 \\
2.32 \pm 1.29\end{array}$ & $\begin{array}{l}2.86 \\
2.86 \\
8.57\end{array}$ & $\begin{array}{l}40.00 \\
42.86 \\
46.67\end{array}$ \\
\hline
\end{tabular}

3.2 Analysis of Less Important Topics

As in the case for the important topics, the results allow to select the less important topics for industry and academia. A less important topic is defined as a topic that received a rating of 1 or 2 from at least $30 \%$ of the participants. Table $\mathbf{6}$ lists the nine topics which are considered less important to both industry and academia, and one topic which is considered less important to academia only. Again, the average ratings for industry and academia are similar for most of the topics, which includes Ad-Hoc Networks, Peer-to-Peer and Grids. The most notable exception is Centralized Management, which is considered not important by $57.1 \%$ of participants in academia, but only by $20.4 \%$ in industry. The obtained ratings indicate a decreasing interest in these topics, and can be taken into account when removing topics from the taxonomy in future revisions.

\subsection{Analysis of Proposed Topics}

Each of the questionnaire participants was given the opportunity to suggest new topics for every category that, in their opinion, should be included in the taxonomy. This was done by adding a text field in which the participants could enter a number of topics as they pleased. Table $\square$ gives an overview of the number of new topics per category that were identified from the questionnaire, and also shows the number of unique topics that were identified through an analysis of the proposed topics. Most topics were proposed in the first two categories, which is a consequence of 
Table 7 Number of topics proposed per category.

\begin{tabular}{lcc}
\hline Category & Topics (total) & Topics (unique) \\
\hline 1. Network Management & 71 & 35 \\
2. Service Management & 38 & 29 \\
3. Business Management & 13 & 9 \\
4. Functional Areas & 27 & 22 \\
5. Management Approaches & 17 & 14 \\
6. Technologies & 25 & 18 \\
7. Methods & 11 & 10 \\
\hline
\end{tabular}

the general nature of these categories and of the fact that participants were not provided with the full taxonomy at once, and thus often proposed topics which were already covered in other categories.

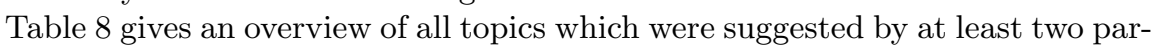
ticipants. Most popular topics in the management categories include InformationCentric Networks, Network Function Virtualization, Home Networks, Content Distribution Networks, Service Integration and Management and Privacy Management. Most of these topics have indeed gotten more attention in recent years, and are valid candidates for the revised taxonomy. Focusing on the category Technologies, the topics Machine Learning and Big Data Analytics have been suggested multiple times. Both topics were in fact already present in the taxonomy, but in the category Methods. This does confirm, however, that these topics have significant importance in the field of network and service management, and should certainly remain in the revised taxonomy.

\section{Analysis of Taxonomy Topics Based on Conference Proceedings}

The answers of the questionnaire illustrate the necessity of updating the original taxonomy to account for current and future directions of the network and service management research field. Similar to previous work, the records of submitted and accepted papers in the field are studied as well, in order to deduce popular topics and current trends. Table $\mathbf{Q}$ shows the percentage of submitted (including rejected) and accepted (inside parenthesis) papers in all editions of NOMS, IM, and CNSM from 2010 to 2015, according to the original taxonomy's specific, individual topic areas, as described in Table $\mathrm{W}$. The percentages are obtained by dividing the number of submitted/accepted papers that address a topic by the total number of submitted/accepted papers of each edition. Numbers which exceed a threshold of $10 \%$, are presented in italics.

Several interesting trends can be observed from these results. The topics Wireless and Mobile Networks and Security, Fault and Performance Management are well ranked along 2010 to 2016, and are expected to continue doing so. This is in line with the obtained answers to the questionnaire, which indicate that these topics are likely to have a high impact in the research field. Other topics, such as Virtual Networks, Software-Defined Networking (SDN) and Monitoring and Measurements, show a strictly increasing trend. This indicates an increased relevance to and interest in the topic, which certainly holds for SDN-based solutions. Other topics, such as IP Networks, Process Management, Performance Management and 
Table 8 New topics proposed by at least two participants.

\begin{tabular}{|c|c|}
\hline Topic & Participants \\
\hline $\begin{array}{l}\text { 1. Network Management } \\
\text { - Information-Centric Networks } \\
\text { - Network Function Virtualization } \\
\text { - Home Networks } \\
\text { - Security and Privacy } \\
\text { - Content Distribution Networks } \\
\text { - Wireless) Mesh Networks } \\
\text { - Opportunistic/Social Networks } \\
\text { - Vehicular Networks } \\
\text { - Body Area Networks } \\
\text { - Cellular Networks / } 5 \text { G Networks } \\
\text { - Cloud Networks } \\
\text { - Cognitive (Radio) Networks } \\
\text { - Enterprise Networks } \\
\text { - Hybrid Networks } \\
\text { - Factory Networks (Industry 4.0) } \\
\text { - Inter-Domain Networks } \\
\text { - Non-IP Networks }\end{array}$ & $\begin{array}{l}6 \\
6 \\
5 \\
5 \\
4 \\
3 \\
3 \\
3 \\
2 \\
2 \\
2 \\
2 \\
2 \\
2 \\
2 \\
2 \\
2\end{array}$ \\
\hline $\begin{array}{l}\text { 2. Service Management } \\
\text { - Service Integration and Management } \\
\text { - Industry 4.0 Services } \\
\text { - Big Data Management } \\
\text { - Information Networking Services } \\
\text { - Personalized and Context-Aware Services } \\
\text { - Service Assurance }\end{array}$ & $\begin{array}{l}4 \\
3 \\
2 \\
2 \\
2 \\
2\end{array}$ \\
\hline $\begin{array}{l}\text { 3. Business Management } \\
\text { - Privacy Management }\end{array}$ & 5 \\
\hline $\begin{array}{l}\text { 4. Functional Areas } \\
\text { - Data Mining and Management of Network Data } \\
\text { - Monitoring and Measurement Management } \\
\text { - Optimization Management } \\
\text { - Privacy and Security Management }\end{array}$ & $\begin{array}{l}3 \\
2 \\
2 \\
2\end{array}$ \\
\hline $\begin{array}{l}\text { 5. Management Approaches } \\
\text { - Hierarchical Management } \\
\text { - Cognitive Management }\end{array}$ & $\begin{array}{l}3 \\
2\end{array}$ \\
\hline $\begin{array}{l}\text { 6. Technologies } \\
\text { - Machine Learning / Data Mining } \\
\text { - (Distributed) (Big) Data Analytics }\end{array}$ & $\begin{array}{l}5 \\
4\end{array}$ \\
\hline $\begin{array}{l}\text { 7. Methods } \\
\text { - Artifical Intelligence }\end{array}$ & 2 \\
\hline
\end{tabular}

Peer-to-Peer, are facing a drop in recent years. This indicates a decreased interest in the community, and means that these topics might be valid candidates for merger or removal of the taxonomy in the near future. It is also worth noting that the topic Wireless Networks is most popular in even years, which could be caused by different interests between NOMS and IM. 
Table 9: Submitted/accepted papers at NOMS, IM and CNSM.

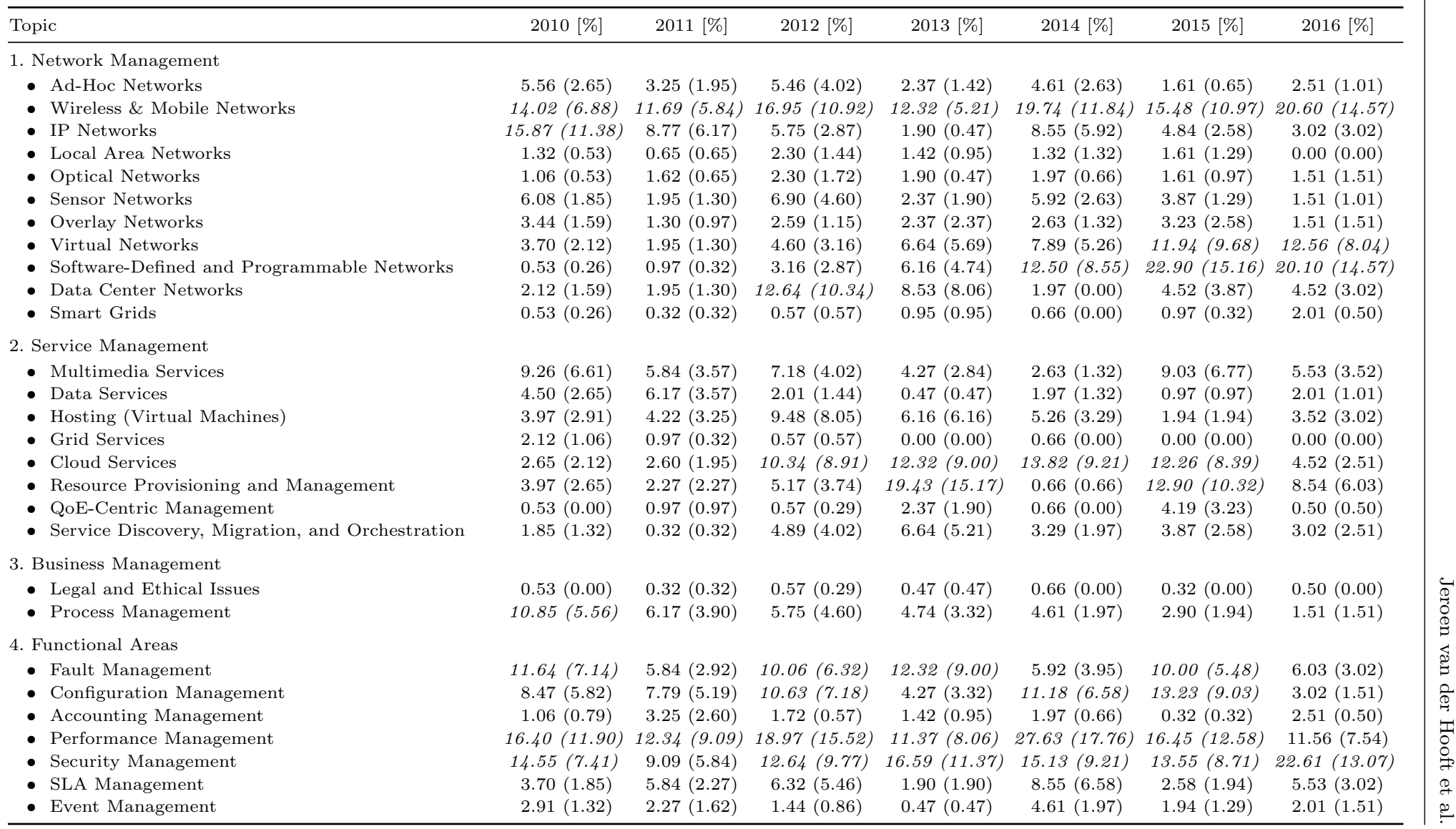


Table 9: Submitted/accepted papers at NOMS, IM and CNSM (continued).

\begin{tabular}{|c|c|c|c|c|c|c|c|}
\hline Topic & $2010[\%]$ & $2011[\%]$ & $2012[\%]$ & $2013[\%]$ & $2014[\%]$ & $2015[\%]$ & $2016[\%]$ \\
\hline \multicolumn{8}{|l|}{ 5. Management Approaches } \\
\hline - Centralized Management & $1.32(1.06)$ & $1.62(1.30)$ & $4.31(3.16)$ & $1.90(0.95)$ & $1.97(1.97)$ & $3.55(2.58)$ & $1.51(1.01)$ \\
\hline - Distributed Management & $11.64(7.14)$ & $7.79(4.87)$ & $10.34(6.61)$ & $5.69(5.21)$ & $9.21(4.61)$ & $4.84(2.90)$ & $7.04(5.03)$ \\
\hline - Autonomic and Self Management & $14.81(9.79)$ & $9.42(6.17)$ & $16.38(11.21)$ & $9.00(6.64)$ & $13.82(9.21)$ & $8.06(5.81)$ & $9.05(8.04)$ \\
\hline - Policy-Based Management & $8.47(5.03)$ & $6.17(3.25)$ & $6.90(4.60)$ & $3.79(2.84)$ & $9.87(5.92)$ & $2.58(1.94)$ & $2.01(1.01)$ \\
\hline - Federated Network Management & $3.97(2.91)$ & $1.62(1.30)$ & $0.57(0.57)$ & $3.32(2.37)$ & $0.66(0.00)$ & $1.29(0.65)$ & $2.51(2.01)$ \\
\hline - Pro-Active Management & $0.00(0.00)$ & $0.32(0.32)$ & $0.29(0.00)$ & $0.95(0.47)$ & $1.32(0.66)$ & $1.29(0.97)$ & $0.50(0.50)$ \\
\hline - Energy-Aware Network Management & $3.17(2.12)$ & $4.22(2.60)$ & $6.61(5.17)$ & $6.64(5.21)$ & $2.63(2.63)$ & $3.55(1.29)$ & $5.53(3.52)$ \\
\hline \multicolumn{8}{|l|}{ 6. Technologies } \\
\hline - Protocols & $7.14(3.17)$ & $2.92(1.95)$ & $4.02(3.16)$ & $12.32(7.58)$ & $9.87(4.61)$ & $10.00(6.13)$ & $5.03(3.52)$ \\
\hline - Middleware & $2.65(1.85)$ & $2.92(1.30)$ & $6.32(4.02)$ & $2.37(1.90)$ & $5.26(3.95)$ & $1.29(0.32)$ & $0.00(0.00)$ \\
\hline - Mobile Agents & $0.79(0.26)$ & $0.65(0.00)$ & $0.86(0.57)$ & $0.47(0.47)$ & $2.63(1.97)$ & $2.58(0.65)$ & $1.01(0.50)$ \\
\hline - Peer-to-Peer & $6.61(4.50)$ & $2.60(1.30)$ & $5.46(2.87)$ & $1.90(1.42)$ & $2.63(1.32)$ & $2.58(1.61)$ & $1.01(1.01)$ \\
\hline - Grids & $0.26(0.26)$ & $0.97(0.65)$ & $0.86(0.57)$ & $0.00(0.00)$ & $0.66(0.00)$ & $0.00(0.00)$ & $0.00(0.00)$ \\
\hline - Data, Information, and Semantic Modeling & $10.05(5.03)$ & $9.09(5.84)$ & $8.91(7.18)$ & $6.64(3.79)$ & $8.55(4.61)$ & $8.06(4.84)$ & $5.03(2.51)$ \\
\hline - Cloud Computing & $5.56(3.17)$ & $8.12(3.90)$ & $8.33(6.03)$ & $24.17(20.38)$ & $13.82(9.87)$ & $11.94(8.06)$ & $8.54(6.53)$ \\
\hline - Internet of Things & $0.26(0.00)$ & $0.00(0.00)$ & $0.86(0.86)$ & $1.42(0.47)$ & $0.66(0.66)$ & $3.23(2.26)$ & $3.52(2.51)$ \\
\hline - Human-Machine Interaction & $1.32(1.32)$ & $0.65(0.65)$ & $0.00(0.00)$ & $0.47(0.47)$ & $0.00(0.00)$ & $0.97(0.32)$ & $1.51(1.01)$ \\
\hline - Operations and Business Support Systems & $1.59(0.26)$ & $0.32(0.32)$ & $1.44(0.57)$ & $1.90(0.95)$ & $0.66(0.66)$ & $1.94(1.61)$ & $0.00(0.00)$ \\
\hline \multicolumn{8}{|l|}{ 7. Methods } \\
\hline - Control Theories & $1.85(1.32)$ & $0.32(0.00)$ & $2.30(1.15)$ & $0.00(0.00)$ & $1.97(1.32)$ & $0.97(0.32)$ & $0.50(0.50)$ \\
\hline - Optimization Theories & $2.65(1.85)$ & $0.65(0.32)$ & $8.33(5.75)$ & $0.95(0.95)$ & $9.21(4.61)$ & $12.58(10.32)$ & $7.54(4.02)$ \\
\hline - Economic Theories & $1.06(0.53)$ & $0.97(0.32)$ & $2.01(1.44)$ & $0.47(0.47)$ & $1.32(1.32)$ & $2.26(1.61)$ & $0.50(0.00)$ \\
\hline - Machine Learning and Genetic Algorithms & $1.59(0.53)$ & $2.60(1.95)$ & $4.31(3.16)$ & $6.64(3.79)$ & $5.92(3.29)$ & $7.74(5.81)$ & $5.03(3.02)$ \\
\hline - Logics & $0.00(0.00)$ & $0.32(0.00)$ & $0.86(0.57)$ & $0.47(0.47)$ & $0.66(0.66)$ & $0.00(0.00)$ & $0.00(0.00)$ \\
\hline - Probabilistic, Stochastic Processes, Queuing Theory & $1.59(1.59)$ & $0.32(0.32)$ & $3.45(2.59)$ & $1.90(1.42)$ & $5.92(3.29)$ & $5.81(4.19)$ & $1.01(1.01)$ \\
\hline - Simulation & $3.44(2.65)$ & $3.25(2.92)$ & $5.75(3.74)$ & $9.48(6.16)$ & $14.47(9.87)$ & $20.97(14.19)$ & $7.54(4.52)$ \\
\hline - Experimental Approach & $2.38(1.32)$ & $1.62(1.30)$ & $6.03(4.31)$ & $9.95(7.11)$ & $13.16(9.87)$ & $28.06(20.32)$ & $6.03(3.52)$ \\
\hline - Prototype Design & $0.53(0.26)$ & $1.62(1.62)$ & $1.72(0.86)$ & $0.47(0.00)$ & $3.29(2.63)$ & $10.65(6.77)$ & $0.50(0.50)$ \\
\hline - Monitoring and Measurements & $4.23(3.17)$ & $4.22(2.92)$ & $5.75(4.89)$ & $10.90(8.06)$ & $9.87(4.61)$ & $11.94(8.06)$ & $4.52(4.02)$ \\
\hline - Data Mining and (Big) Data Analytics & $0.79(0.79)$ & $1.30(1.30)$ & $0.86(0.86)$ & $7.11(6.64)$ & $1.97(1.97)$ & $7.74(5.16)$ & $4.02(2.51)$ \\
\hline
\end{tabular}




\section{Updated Network and Service Management Taxonomy}

Based on the analysis of the survey results and the proceedings of IM, NOMS and CNSM, as well as on discussions during a physical meeting at CNSM 2015, the following changes to the taxonomy categories and topics have been made:

1. Network Management

- Add Information-Centric Networks

- Add Home Networks

- Add Access Networks

- Add Enterprise and Campus Networks

- Add SCADA Networks and Distributed Control Systems

- Remove Ad-Hoc Networks

- Remove Local Access Networks

- Remove Smart Energy Grids

2. Service Management

- Add Content Delivery Services

- Add Internet Connectivity and Access Services

- Add Information Technology Services

- Remove Data Services

- Remove Hosting (Virtual Machines)

3. Business Management

- Add Multi-Steakeholder Aspects

- Add Service Level Agreements

- Add Lifecycle Aspects

- Add Process and Workflow Aspects

- Remove Ethical Issues

4. Functional Areas

- Remove SLA Management

- Remove Event Management

5. Management Approaches

- Merge Autonomic and Self Management with Cognitive Management

6. Technologies

- Add Overlay Networks

- Add Information Visualization

- Add Orchestration

- Remove Peer-to-Peer

- Remove Resource Provisioning

- Remove Human-Machine Interaction

7. Methods

- Add Evolutionary Algorithms

- Add Field Experiments

- Remove Experimental Approach 
Table 10 Updated network and service management taxonomy, available onlinem.

1. Network Management

- IP Networks

- Wireless Networks and Cellular Networks

- Optical Networks

- Overlay Networks

- Virtual Networks

- Home Networks

- Access Networks

- Enterprise and Campus Networks

- Data Center Networks

- SCADA Networks and Distributed Control Systems

- Wireless Sensor Networks

- Internet of Things Networks

- Information-Centric Networks

- Software-Defined Networks

2. Service Management

- Multimedia Services

- Content Delivery Services

- Cloud Computing Services

- Internet Connectivity and Access Services

- Internet of Things Services

- Security Services

- Context-Aware Services

- Information Technology Services

3. Business Management

- Economic Aspects

- Multi-Stakeholder Aspects

- Service Level Agreements

- Lifecycle Aspects

- Process and Workflow Aspects

- Legal Perspective

- Regulatory Perspective

- Privacy Aspects

4. Functional Areas

- Fault Management

- Configuration Management

- Accounting Management

- Performance Management

- Security Management
5. Management Paradigms

- Centralized Management

- Hierarchical Management

- Distributed Management

- Federated Management

- Autonomic and Cognitive Management

- Policy-Based Management

- Pro-Active Management

- Energy-Aware Management

- QoE-Centric Magement

6. Technologies

- Communication Protocols

- Middleware

- Overlay Networks

- Cloud Computing and Cloud Storage

- Data, Information and Semantic Modeling

- Information Visualization

- Software-Defined Networking

- Network Function Virtualization

- Orchestration

- Operations and Business Support Systems

7. Methods

- Mathematical Logic and Automated Reasoning

- Mathematical Optimization

- Control Theory

- Probability Theory, Stochastic Processes and Queuing Theory

- Machine Learning

- Evolutionary Algorithms

- Economic Theory and Game Theory

- Network Monitoring and Measurements

- Data Mining and (Big) Data Analysis

- Computer Simulation Experiments

- Prototype Implementation and Testbed Experimentation

- Field Experiments

In addition, some topics have been renamed to better reflect their purpose. Along with the changes proposed in Section $\$$, these changes result in the taxonomy presented in Table [0. It is worth noting that in most cases, removed topics are covered by broader topics. For instance, Peer-to-Peer is covered by Overlay Networks and Smart Energy Grids is covered by SCADA Networks.

\footnotetext{
${ }^{1}$ https://en.wikipedia.org/wiki/network_and_service_management_taxonomy
} 
New topics included in the taxonomy represent increased interest, from both academia and industry, in aspects that were previously absent. Because of this new interest, some considerations about each new topic in the taxonomy are drawn below.

- Information-Centric Networks - This topic includes all aspects related to moving the Internet infrastructure away from a host-centric paradigm based on perpetual connectivity and the end-to-end principle, to a network architecture in which the focal point is named information, data or content;

- Home Networks - This topic covers computer networks that facilitate communication among devices within the close vicinity of a home. Devices capable of participating in this network, such as network printers and handheld mobile computers, often gain enhanced emergent capabilities through their ability to interact;

- Access Networks - This topic encompasses all aspects related to the management of access networks, which connect telecommunications subscribers to their immediate service provider;

- Enterprise and Campus Networks - This topic relates to the management of campus networks, essentially an interconnection of local area networks within a limited geographical area;

- SCADA Networks and Distributed Control Systems - This topic includes all aspects of supervisory control and data acquisition and control systems, used to enable the monitoring, logging and issuing of process commands;

- Content Delivery Services - This topic covers all aspects of content delivery networks (CDN), which distribute services spatially relative to end-users to provide high availability and high performance. CDNs serve most of today's web pages and services, live and on-demand media content and social networks;

- Internet Connectivity and Access Services - This topic deals with all aspects related to Internet connectivity and Internet access, covering both hardwired and wireless solutions;

- Internet Technology Services - This topic includes all aspects related to IT service management, the whole of activities performed by an organization to plan, design, deliver and operate IT services.

- Multi-Stakeholder Aspects - This topic covers all aspects of the multi-stakeholder governance model, in which stakeholders are brought together to participate in the design and implementation of solutions that target common problems.

- Service Level Agreements - With the increased performance and complexity of today's network and service management solutions, different targets have to be met by the provider. This topic encompasses all aspects of service level agreements between the provider and the client.

- Lifecycle Aspects - This topic encompasses all aspects related to process lifecycle, a way to look at processes in the context of their initial, maturing and final stages of evolution and growth.

- Process and Workflow Aspects - This topic contains all aspects of processes and workflows, focusing on the procession of information related to network and service management. 
- Overlay Networks - This topic includes all aspects of overlay networks, both in telecommunication and in the Internet infrastructure;

- Information Visualization - This topic pertains to all technological aspects of information visualization, the study of visual representations of abstract data to reinforce human cognition;

- Orchestration - This topic includes all aspects of orchestration, in the context of service-oriented network architectures, network virtualization and resource provisioning;

- Evolutionary Algorithms - This topic focuses on all aspects of evolutionary algorithms. Starting from candidate solutions to an optimization problem, these algorithms use mechanisms inspired by biological evolution, such as reproduction, mutation and selection, to evolve towards an optimal solution;

- Field Experiments - This topic is related with field experiments, in which the scientific method is applied to experimentally examine an intervention in a real-word context rather than in the laboratory.

Although the list of new topics is an extensive one, it is not necessarily complete; after all, defining emerging topics in a young and dynamic research field is not an unambiguous process. In the future, regular revisions of the taxonomy (i.e., every two years) will thus be requested.

\section{Summary and Conclusions}

In this paper, an updated version of the taxonomy for the network and service management research field was introduced. To this end, a questionnaire-based survey was conducted among experts from industry and academia. Based on the questionnaire's answers, an analysis was performed concerning important and less important topics in the original taxonomy. Furthermore, an analysis was carried out on the topics of papers submitted to the most important conferences in the community (i.e., NOMS, IM and CNSM). The obtained results were discussed during a physical meeting at CNSM 2015, based on which a number of topics were added, removed and merged. A comprehensive list of changes has been presented in this paper, along with some considerations on each new topic.

The taxonomy presented in this paper has already been used at CNSM 2016 and IM 2017, and is currently used for IEEE Transactions on Network and Service Management (TNSM). It is expected to be increasingly used in efforts related to the network and service management field, including public or private open calls for project funding, special issues of journals and future conferences in the network and service management field. Given the dynamic nature of the field, an update of the taxonomy is expected in the near future, further improving the categorization and incorporating emerging topics.

Acknowledgements Jeroen van der Hooft is funded by grant of the Agency for Innovation and Entrepreneurship in Flanders (VLAIO). The research was performed partially within Flamingo, a Network of Excellence project (318488) supported by the European Commission under its Seventh Framework Programme. The authors are grateful to all participants from the IEEE CNOM and IFIP WG6.6 community to the online questionnaire and the physical CNOM/WG6.6 meetings co-located with the recent NOMS, IM, CNSM and IEEE Globecom conferences, where the taxonomy updates were discussed and finally agreed upon. 


\section{References}

1. ACM: The 2012 ACM Computing Classification System. ACM Publications. http://www.acm.org/publications/class-2012 (2012). Accessed 25 August 2017

2. dos Santos, C.R.P., Famaey, J., Schönwälder, J., Granville, L.Z., Pras, A., De Turck, F.: Taxonomy for the Network and Service Management Research Field. Journal of Network and Systems Management 24(3), 764-787 (2016)

Jeroen van der Hooft obtained his M.Sc. degree in Computer Science Engineering from Ghent University, Belgium, in July 2014. In August of that year, he joined the Department of Information Technology at Ghent University-imec, where he is currently active as a Ph.D. student. His main research interest is the end-to-end Quality of Experience optimization in adaptive video streaming.

Maxim Claeys obtained his M.Sc. and Ph.D. degree in Computer Science Engineering from Ghent University, Belgium, in 2012 and 2017, respectively. His research focused on the end-to-end Quality of Experience optimization, ranging from the design of autonomous clients to intelligent in-network decision taking. He is currently active as a post-doctoral fellow at the IDLab group at the University of Antwerp, Belgium.

Niels Bouten obtained his M.Sc. and Ph.D. degree in Computer Science Engineering from Ghent University, Belgium, in 2011 and 2016, respectively. His research focused on end-to-end Quality of Experience optimization, providing specific solutions for HTTP adaptive streaming and how these can be applied in a virtualized network environment. He is currently active as product manager at Televic Rail, Belgium.

Tim Wauters obtained his M.Sc. and Ph.D degree in Electro-technical Engineering from Ghent University, Belgium, in 2001 and 2007, respectively. He is currently active as a post-doctoral fellow at the Department of Information Technology at Ghent University-imec. His research interests include network and service architectures, and management solutions for multimedia delivery services.

Jürgen Schönwälder obtained his M.Sc. and Ph.D. degree in Computer Science from the Technical University Braunschweig, Germany, in 1990 and 1996, respectively. Since 2003, he is professor of Computer Science at Jacobs University Bremen. His research interests include network management, network measurement, network security and distributed systems.

Aiko Pras is professor in the area of network operations and management at the University of Twente, the Netherlands. He obtained a Ph.D. degree for his thesis titled "Network Management Architectures". His research interests include network management technologies, network monitoring, measurements and security. He is steering committee member of several conferences, including IM/NOMS and CNSM, and series/associate editor of IJNM and TNSM.

Burkhard Stiller obtained his Diploma (M.Sc.) in Computer Science and Dr. rer.-nat. degree from the University of Karlsruhe, Germany, in 1990 and 1994, respectively. He is currently a full professor at the University of Zrich UZH, Switzerland, where he leads the Communication Systems Group CSG. His research interests include charging and accounting, overlay networks and blockchains, economic and network/service management, and regulatory aspects of communications.

Marinos Charalambides obtained his M.Sc. degree in Communications Networks and Software from the University of Surrey, the United Kingdom, in 2002. In 2008, he obtained his Ph.D degree from the same university. He is currently active as a research associate at University College London, the United Kingdom, where he has been involved in several research projects and courses. His research interests are in the area of network and service management.

Rémi Badonnel obtained his M.Sc. degree in Computer Engineering from ESIAL, Nancy, France, in 2003. In 2008, he obtained his Ph.D. degree in Computer Science from Henri-Poincaré University, Nancy, France. He is currently active as an associate professor of Computer Science at the TELECOM Nancy Engineering School, University of Lorraine, France. His research interests are focused on network and service management, smart and autonomic environments, and the Internet of Things.

Joan Serrat obtained his M.Sc. and Ph.D. degree in Telecommunications Engineering from the Universitat Politcnica de Catalunya (UPC), Spain, where he has been active as a full professor since 2008. He is currently leading the UPC research group MAPS in the Management of the Future Internet (FLAMINGO), a Network of Excellence Project supported by the European Commission. His research interests are in network and service management and enabling technologies. 
Carlos Raniery Paula dos Santos obtained his M.Sc. degree in Computer Science from the Federal University of Rio Grande do Sul, Brazil, in 2008. In 2013, he obtained his Ph.D. degree in Computer Science from the same university. He is currently active as an adjunct professor at the Federal University of Santa Maria, Brazil, where he has been involved in several supervision and education activities on undergraduate and graduate courses.

Filip De Turck obtained his M.Sc. and Ph.D. degree in Electronic Engineering from Ghent University, Belgium, in 1997 and 2002, respectively. He is currently active as a full professor at Ghent University-imec, where he leads the network and service management research group at the Department of Information Technology. His research interests include telecommunication network and service management, and design of efficient virtualized network systems. 